\title{
A Series-Fed Linear Substrate-Integrated Dielectric Resonator Antenna Array for Millimeter-Wave Applications
}

\author{
Ke Gong $\mathbb{D}^{1},{ }^{1}$ Xue Hui Hu, ${ }^{1}$ Peng Hu, ${ }^{1}$ Bing Jie Deng, ${ }^{1}$ and You Chao $\mathrm{Tu}^{2}$ \\ ${ }^{1}$ College of Physics and Electronic Engineering, Xinyang Normal University, Xinyang 464000, China \\ ${ }^{2}$ Collaborative Innovation Center of Henan Province for Energy-Saving Building Materials, Xinyang 464000, China \\ Correspondence should be addressed to Ke Gong; gongkexynu@163.com
}

Received 11 December 2017; Revised 12 February 2018; Accepted 28 February 2018; Published 22 April 2018

Academic Editor: Muhammad Ramlee Kamarudin

Copyright ( $\odot 2018 \mathrm{Ke}$ Gong et al. This is an open access article distributed under the Creative Commons Attribution License, which permits unrestricted use, distribution, and reproduction in any medium, provided the original work is properly cited.

\begin{abstract}
A series-fed linear substrate-integrated dielectric resonator antenna array (SIDRAA) is presented for millimeter-wave applications, in which the substrate-integrated dielectric resonator antenna (SIDRA) elements and the feeding structure can be codesigned and fabricated using the same planar process. A prototype $4 \times 1$ SIDRAA is designed at $\mathrm{Ka}$-band and fabricated with a two-layer printed circuit board (PCB) technology. Four SIDRAs are implemented in the Rogers RT6010 substrate using the perforation technique and fed by a compact substrate-integrated waveguide (SIW) through four longitudinal coupling slots within the Rogers RT5880 substrate. The return loss, radiation patterns, and antenna gain were experimentally studied, and good agreement between the measured and simulated results is observed. The SIDRAA example provides a bandwidth of about $10 \%$ around $34.5 \mathrm{GHz}$ for $10 \mathrm{~dB}$ return loss and stable broadside radiation patterns with the peak gain of $10.5-11.5 \mathrm{dBi}$ across the band.
\end{abstract}

\section{Introduction}

Dielectric resonator antennas (DRAs) have received widespread attention because of a number of advantages such as small size, high radiation efficiency, wider impedance bandwidth, low conductor loss, no excitation of surface waves, easy of excitation, and so on $[1,2]$. These advantages make DRAs excellent candidates for wireless communication systems, especially the ones operated in the millimeter-wave band [3]. Compared with the traditional microstrip antenna and other planar metallic antennas, DRAs also possess higher radiation efficiency for high-frequency applications. However, DRAs are commonly low-gain antennas with a broad radiation pattern for the practical application, and various methods for gain enhancement of single-element DRAs have been reported in the literature $[4,5]$.

Recently, more effort has been devoted to DRA array design to increase the antenna gain for various microwave/ millimeter-wave systems [6-17]. Linear rectangular DRA arrays fed by the dielectric image guide (DIG) were investigated at $X$-band $[6,7]$, and a DIG-fed double-sided DRA array was proposed at $\mathrm{Ka}$-band with a peak gain of $15.8 \mathrm{dBi}$
[8]. By adding the reflector plane, the eight-element linear DRA array achieved the highest $15.7 \mathrm{dBi}$ gain for microwave application [9]. A significant increase in gain was obtained in [10] by using close interelement spacing for parasitic DRA elements. A compact wideband $2 \times 2$ DRA array was designed in [11] with the peak gain of $10.5 \mathrm{dBi}$ for microwave imaging systems. A $2 \times 2$ cylindrical DRA array offered a maximum gain of $14.8 \mathrm{dBi}$ utilizing a nonresonant microstrip patch technique at $X$-band [12]. Substrate-integrated waveguide- (SIW-) parallel-fed rectangular $1 \times 8$ and series-fed $4 \times 1$ DRA arrays were studied and presented together with its circuit model at $\mathrm{Ka}$-band $[13,14]$. An SIW-integrated two-dimensional $8 \times 8$ DRA array was designed in [15] with the measured gain of $21.6 \mathrm{dBi}$ over the operating frequency band 35-37 GHz. A 180-element linear polarized DRA array fed by radial-line waveguide was reported [16] and achieves a maximum gain of $26.7 \mathrm{dBi}$ from 11.96 to $12.08 \mathrm{GHz}$. Circularly polarized $2 \times 2$ wideband DRA array and low-sidelobelevel $1 \times 6$ DRA array achieved a peak gain of $12.17 \mathrm{dBi}$ and $13.43 \mathrm{dBi}$ at $C$-band, respectively [17]. However, for the abovementioned arrays in [6-17], the DRA elements are usually fabricated singly and assembled one by one, which means 


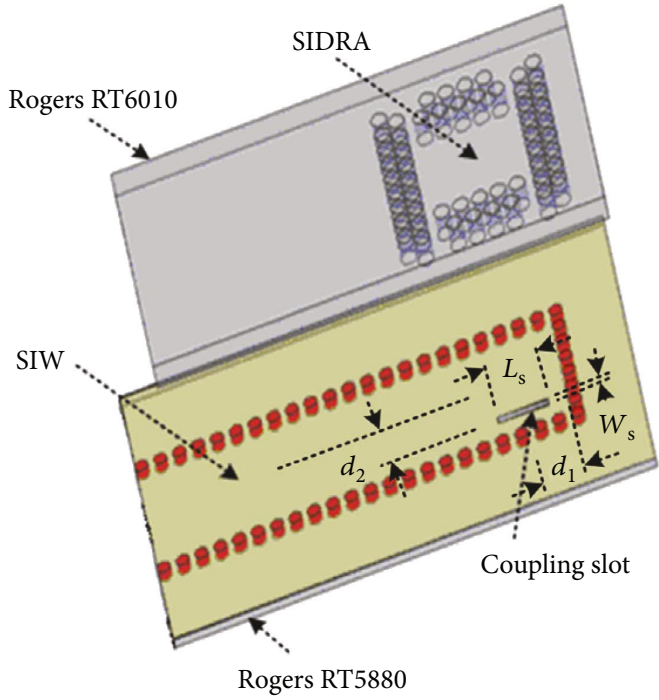

(a)

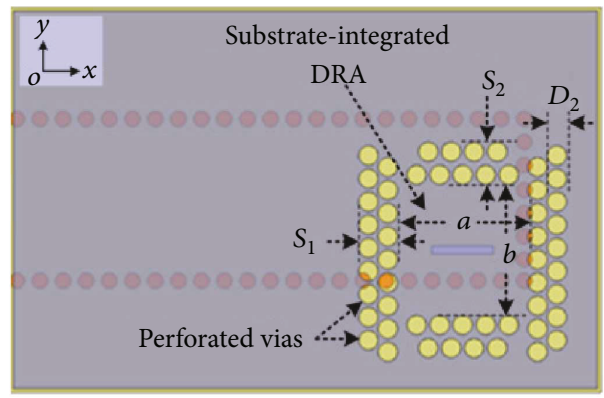

(b)

FIGURE 1: Structure of the SIDRA element with the longitudinal coupling slot. (a) 3D view and (b) top view. $\left(L_{\mathrm{s}}=1.6, W_{\mathrm{s}}=0.2, d_{1}=2.15\right.$, $d_{2}=0.55$, all in $\mathrm{mm}$ ).

higher cost and larger mounting errors, especially for the large-scale arrays in millimeter-wave band. In order to improve the accuracy of the DRA array productions, a novel cofabricated approach for millimeter-wave DRA array designs was demonstrated using the multilayer printed circuit board (PCB) technology [18]. However, the separated DRA elements are fabricated by removing the surrounding dielectric materials, and the feeding network is relatively complex. In our previous work, a substrate-integrated dielectric resonator antenna (SIDRA) was demonstrated with PCB process [19]. However, the SIDRA in [19] is not suitable for compact array application because the transverse coupling slot requires the spacing between two adjacent SIDRA elements to be $\lambda_{\mathrm{g}}\left(\lambda_{\mathrm{g}}\right.$ is the guided wavelength in feeding SIW) for cophase exciting.

Moreover, different feeding techniques have been used to feed an array of DRAs, such as the dielectric image guide feed [6-8], the microstrip line feed $[9-12,17]$, the radial-line waveguide feed [16], and the SIW feed [13-15, 18]. Although the microstrip line feeding network is the most frequently employed, its power loss dominates as the operating frequency increases. In contrast, the SIW is a high Q-structure since it is a good compromise between an air-filled rectangular waveguide and a microstrip line [20]. Accordingly, it can minimize the radiation loss and parasitic radiation and provides a low-cost, compact, and low-profile feeding network.

In this article, a series-fed linear substrate-integrated dielectric resonator antenna array (SIDRAA) is designed for millimeter-wave applications, in which four SIDRA elements are implemented in the substrate using the perforation technique and fed by a compact SIW feeding network through four longitudinal coupling slots with a distance of $\lambda_{\mathrm{g}} / 2$, and the SIDRA elements along with the feeding structure can be codesigned and fabricated conveniently using the standard PCB process. The proposed SIDRAA has the advantages of low cost, low profile, easy manufacture, compact size, and convenient integration with other planar circuits. In the design, both the SIDRA element and the SIDRAA are simulated and optimized by using Ansoft High Frequency Structure Simulator (HFSS).

\section{Design of the Antenna Element}

2.1. Antenna Configuration. Figure 1 shows the geometry and parameters of the SIDRA element, including the 3D and top views. The antenna element is mainly composed of two parts: an SIDR and a feeding SIW. The SIDR is integrated in the top Rogers $R T 6010\left(\varepsilon_{\mathrm{r} 1}=10.2, \tan \delta=0.0031\right.$ at $10 \mathrm{GHz}$, thickness $h_{1}=0.635 \mathrm{~mm}$ ) substrate using the perforation technique with $S_{1} \geq \lambda_{0} / 10$ and $S_{2} \geq \lambda_{0} / 10\left(\lambda_{0}\right.$ is the wavelength at center frequency in free space) [19]. The end-shorted feeding SIW is constructed in the bottom Rogers RT5880 substrate $\left(\varepsilon_{\mathrm{r} 2}=2.2\right.$, $\tan \delta=0.0013$ at $10 \mathrm{GHz}$, thickness $h_{2}=0.254 \mathrm{~mm}$ ) supporting the dominant mode of $\mathrm{TE}_{10}$ within the antenna operating bandwidth. A longitudinal slot with length of $L_{\mathrm{s}}$ and width of $W_{s}$ is etched on the SIW broad wall in order to couple the energy to the SIDR element. The distance $d_{1}$ from the center of slot to the SIW short-circuited end is initially chosen to be $\lambda_{\mathrm{g}} / 4\left(\lambda_{\mathrm{g}}\right.$ is the guided wavelength) for the maximum coupling [13], and $d_{2}$ is the slot offset from the centerline of SIW for good matching. The center of the SIDR is the same as the center of the coupling slot, and the SIDRA element operates at the dominant $\mathrm{TE}_{111}^{x}$ mode for radiation. The dielectric waveguide model $[2,21]$ has been employed to evaluate the 


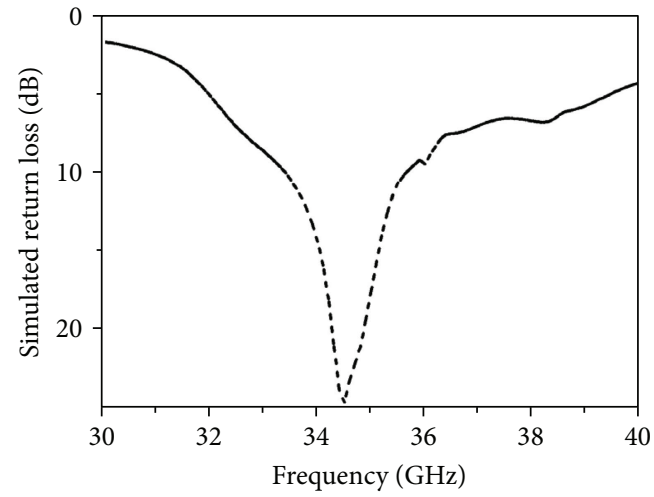

FIgURE 2: Simulated return loss of the SIDRA element.

dimensions of the SIDRA element with the dominant mode for the resonant frequency $f_{0}$ of $34.5 \mathrm{GHz}$ as

$$
\begin{aligned}
f_{0} & =\frac{c}{2 \pi \sqrt{\varepsilon_{\mathrm{r} 1}}} \sqrt{k_{x}^{2}+k_{y}^{2}+k_{z}^{2}}, \\
k_{x} & =\frac{\pi}{a}, \\
k_{z} & =\frac{\pi}{2 h_{1}}, \\
k_{y} \tan \left(\frac{k_{y} b}{2}\right) & =\sqrt{\left(\varepsilon_{\mathrm{r} 1}-1\right) k_{0}^{2}-k_{y}^{2}}, \\
k_{x}^{2}+k_{y}^{2}+k_{z}^{2} & =\varepsilon_{\mathrm{r} 1} k_{0}^{2},
\end{aligned}
$$

where $\varepsilon_{\mathrm{r} 1}$ is the relative permittivity of the SIDRA, $c$ is the speed of light, $h_{1}$ is the thickness of the Rogers RT6010 substrate, $k_{0}$ is the wavenumber in free space, and $k_{x}, k_{y}$, and $k_{z}$ indicate the wavenumbers along $x, y$, and $z$-directions, respectively. Alternatively, the above equations may be used to determine the dimensions of the SIDR for a desired operation frequency. For example, the resonant frequency of $f_{0}=34.5 \mathrm{GHz}$ corresponds to an SIDR with dimensions $a=b=3.45 \mathrm{~mm}$ and $h_{1}=0.635 \mathrm{~mm}$. The other geometric parameters of the SIDR and the feeding SIW (including $W_{\text {siw }}$, $D_{1}, P_{1}, W_{\mathrm{t}}, L_{\mathrm{t}}, W_{\mathrm{m}}, D_{2}, S_{1}$, and $S_{2}$ ) can be obtained from the method of references $[19,20]$. Then, these parameters along with $L_{s}$ and $W_{s}$ are optimized by using HFSS for good matching and high radiation performance.

2.2. Simulated Results. Figure 2 shows the simulated return loss of the SIDRA element. It can be seen that the element exhibits a $10 \mathrm{~dB}$ bandwidth of around $10 \%$. The simulated radiation patterns of the SIDRA at $34.5 \mathrm{GHz}$ are presented in Figure 3, and it can be seen that the $3 \mathrm{~dB}$ beamwidths in the $E(y z)$ - and $H(x z)$-planes are about $140^{\circ}$ and $70^{\circ}$, respectively. The simulated gain of the element is $4.9-5.6 \mathrm{dBi}$ over the operating bandwidth.

\section{Design of the Linear SIDRAA}

3.1. Array Configuration. Employing the SIDRA elements as the building blocks, an $N \times 1$ linear SIDRAA with series-

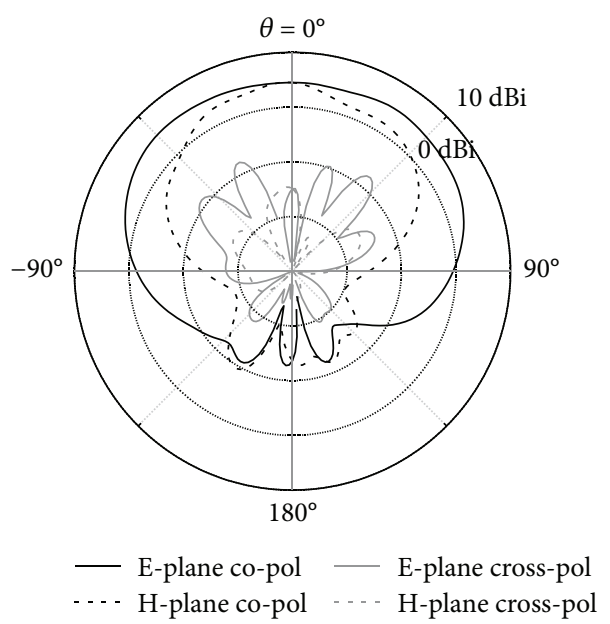

FIgURE 3: Simulated radiation patterns of the SIDRA element at $34.5 \mathrm{GHz}$.

feeding structure can be constructed conveniently by means of the PCB technique. As shown in Figure 4, a $4 \times 1$ SIDRAA example is designed and simulated for $\mathrm{Ka}$-band applications, in which some geometric parameters are set to be $W_{\text {siw }}=4.2 \mathrm{~mm}, D_{1}=0.4 \mathrm{~mm}, P_{1}=0.6 \mathrm{~mm}, D_{2}=0.5 \mathrm{~mm}$, $S_{1}=1 \mathrm{~mm}, S_{2}=1.22 \mathrm{~mm}, W_{\mathrm{t}}=1.3 \mathrm{~mm}, L_{\mathrm{t}}=4.5 \mathrm{~mm}$, $W_{\mathrm{m}}=0.75 \mathrm{~mm}, L_{\text {ground }}=35 \mathrm{~mm}$, and $W_{\text {ground }}=10 \mathrm{~mm}$. The distance between the adjacent SIDRA elements is $L_{x}=\lambda_{\mathrm{g}} / 2=4.4 \mathrm{~mm}\left(\lambda_{\mathrm{g}}\right.$ is the guided wavelength in feeding SIW), corresponding to about $0.51 \lambda_{0}\left(\lambda_{0}\right.$ is the wavelength at the resonant frequency of the SIDRA in free space). On the other hand, the four elements are positioned at the opposite sides of the feeding-SIW centerline, providing an addition phase shift of $\pi$ between any two successive slot fields. Thus, the phase difference between the neighboring elements is $2 \pi$, and the array elements are excited in phase. The other optimized geometric parameters are given as follows: $a=3.4 \mathrm{~mm}, b=3.4 \mathrm{~mm}, L_{\mathrm{s}}=1.6 \mathrm{~mm}$, $W_{\mathrm{s}}=0.2 \mathrm{~mm}, d_{1}=2.3 \mathrm{~mm}, d_{2}=0.5 \mathrm{~mm}$.

A $4 \times 1$ SIDRAA prototype was implemented with a two-layer PCB process. Figure 5 shows the component parts and the assembled prototype of the fabricated array, in which the SIDRA elements are integrated in a singleside Rogers RT6010 substrate and are combined with the RT5880-based SIW feeding structure by using a little bonding glue.

3.2. Simulated and Measured Results. The return loss of the prototype was measured with the Agilent E8363B vector network analyzer. For testing convenience, a wideband microstrip-SIW taper transition was employed in the design. Figure 6 depicts the measured and simulated return losses, and the measured return loss follows the trend of the wellsimulated one with a slight deterioration, namely, $9.5 \mathrm{~dB}$ at $34.2 \mathrm{GHz}$, which may be caused by fabrication tolerance and permittivity fluctuation. The SIDRAA offers a measured bandwidth of about $10 \%$ (from 32.2 to $35.8 \mathrm{GHz}$ ) for $10 \mathrm{~dB}$ return loss. 


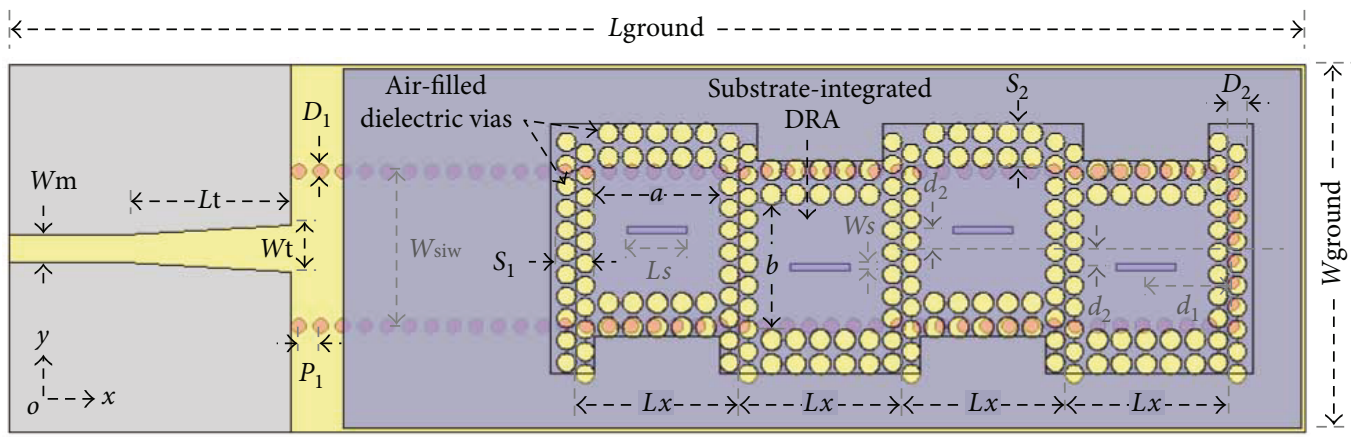

FIgURE 4: Structure of the proposed linear SIDRAA.

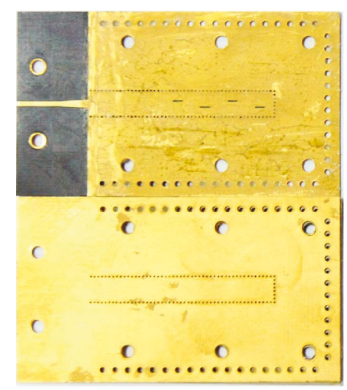

(a)

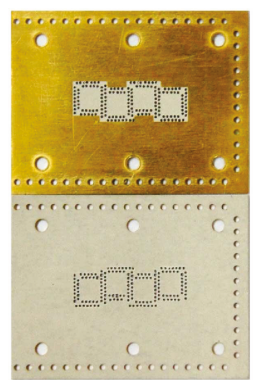

(b)

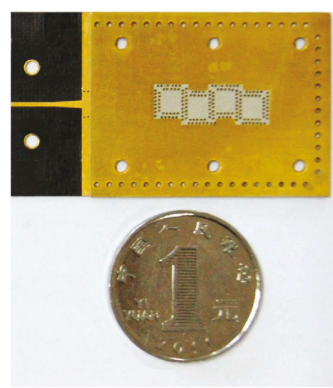

(c)

FIGURE 5: Photograph of fabricated SIDRAA. (a) Series-feeding SIW, (b) SIDRAs, and (c) assembled linear SIDRAA.

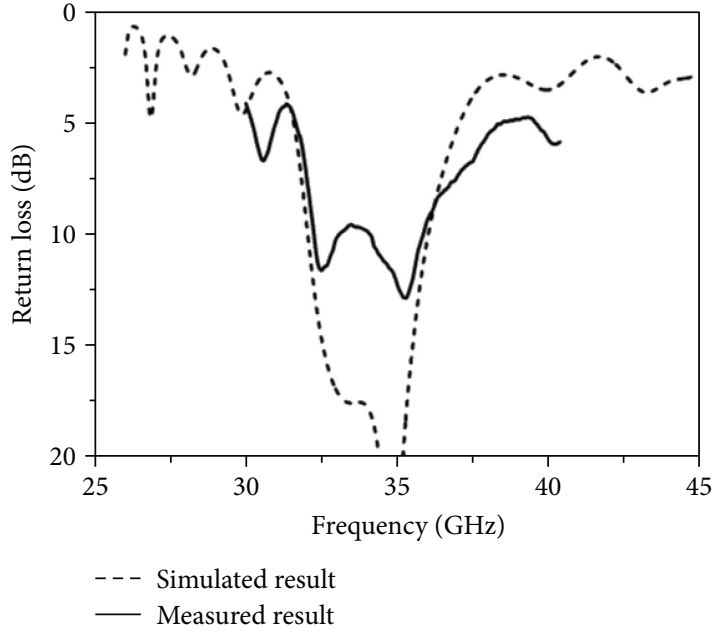

FIGURE 6: Simulated and measured return loss of the proposed SIDRAA.

The antenna prototype was also measured in a far-field anechoic chamber. Figure 7 describes the measured and simulated normalized radiation patterns at $34.5 \mathrm{GHz}$, and reasonable agreement between simulation and experiment is obtained. The radiation patterns are broadside and nearly symmetric in both $E(y z)$ - and $H(x z)$-planes, and the measured $3 \mathrm{~dB}$ beamwidths in the two planes are about $140^{\circ}$ and $60^{\circ}$, respectively. Meanwhile, the cross-polarization levels less than $-18 \mathrm{~dB}$ in $E$-plane and $-20 \mathrm{~dB}$ in $H$-plane are observed. Radiation patterns of other frequencies in the passband are also measured and stable and not shown for brevity.

The measured gain of the SIDRAA was obtained using the gain transfer method where a standard gain horn was used as a reference, and it is illustrated in Figure 8. The measured gain varies between 10.5 and $11.5 \mathrm{dBi}$ over the passband with an average gain of 11.2 $\mathrm{dBi}$. As shown in Figure 8, there is about $0.5 \mathrm{~dB}$ drop in the measured gain compared with the simulated one, and the fluctuation of the measured gain is less than $1 \mathrm{~dB}$ over the operating bandwidth.

\section{Conclusions}

A series-fed linear SIDRAA has been proposed and investigated for millimeter-wave applications. The SIDRA elements are integrated conveniently in the substrate using the perforation technique, and the feeding structure can be codesigned and fabricated using the same planar process. The proposed methodology provides a convenient and low-cost strategy for the design of the DRA arrays. A prototype $4 \times 1$ SIDRAA was designed at $\mathrm{Ka}$-band and fabricated with a two-layer PCB technology. The return loss, radiation patterns, and array antenna gain were experimentally studied, and good agreement between the measured and simulated results was observed. The SIDRAA example exhibits a bandwidth of about $10 \%$ around $34.5 \mathrm{GHz}$ for $10 \mathrm{~dB}$ return loss and stable broadside radiation patterns 


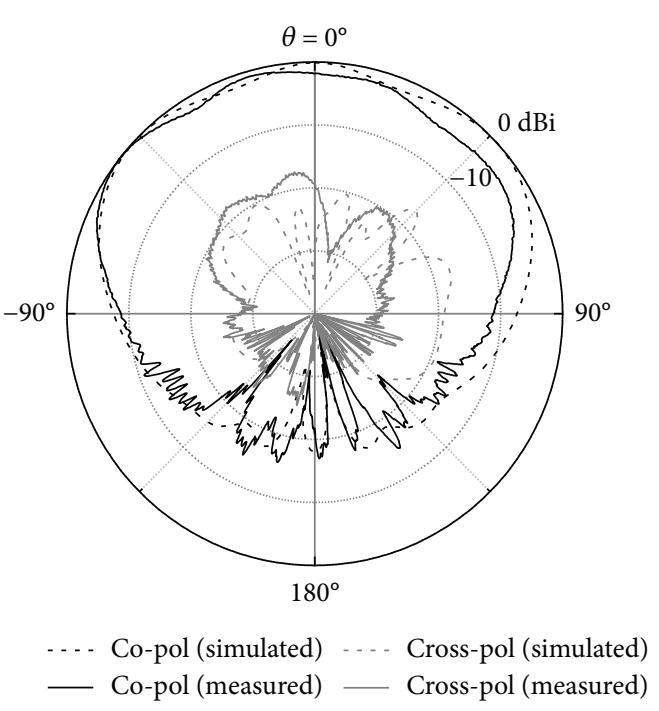

(a)

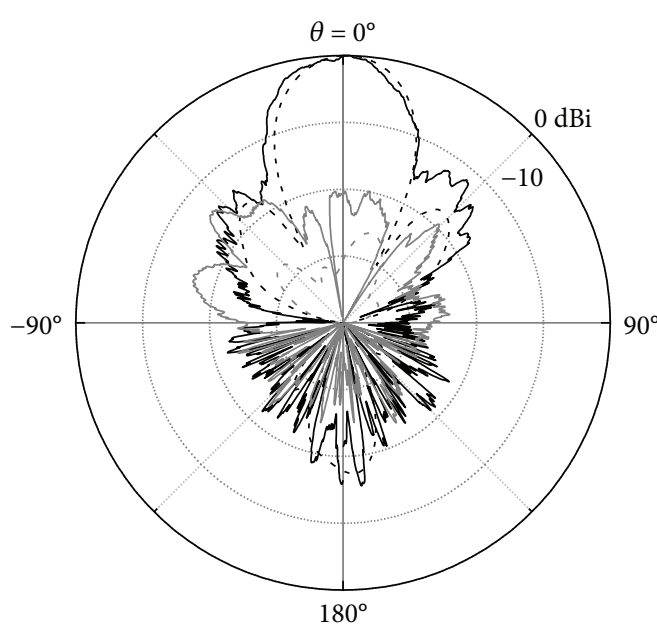

... Co-pol (simulated) - ... Cross-pol (simulated)

— Co-pol (measured) — Cross-pol (measured)

(b)

FIGURE 7: Simulated and measured normalized radiation patterns of the proposed SIDRAA at $34.5 \mathrm{GHz}$. (a) $E(y z)$-plane and (b) $H(x z)$-plane.

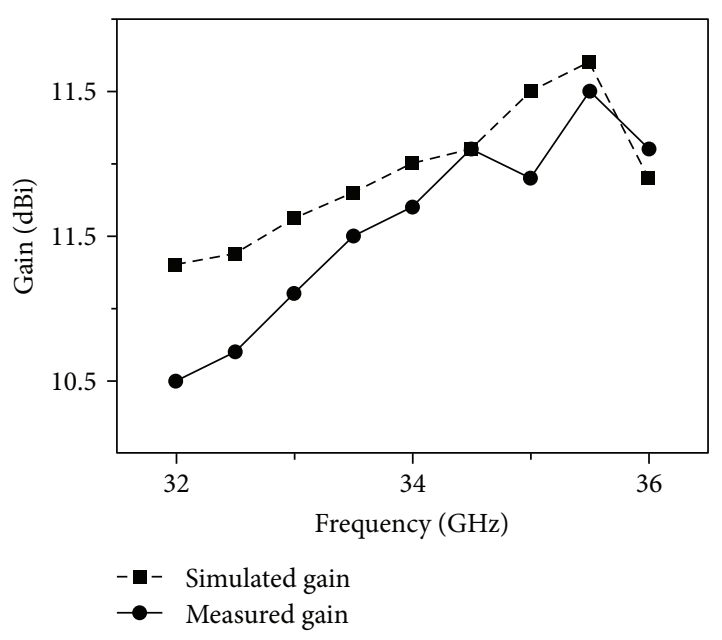

FIGURE 8: Simulated and measured gains of the proposed SIDRAA.

with an average gain of $11.2 \mathrm{dBi}$ across the band. The proposed linear SIDRAA features the advantages of low cost, low profile, easy manufacture, and convenient integration with other planar circuits, and it can be developed to an $N \times N$ planar array for higher antenna gain.

\section{Conflicts of Interest}

The authors declare that they have no competing interests.

\section{Acknowledgments}

This work was supported in part by the National Nature Science Foundation of China (NSFC) under Grant 61571386, Sci-Tech Development Project of Henan Province under Grant 142102210483, Innovation Scientists and Technicians Troop Construction Projects of Henan Province, and Nanhu Scholars Program for Young Scholars of XYNU.

\section{References}

[1] A. Petosa and A. Ittipiboon, "Dielectric resonator antennas: a historical review and the current state of the art," IEEE Antennas and Propagation Magazine, vol. 52, no. 5, pp. 91-116, 2010.

[2] S. Keyrouz and D. Caratelli, "Dielectric resonator antennas: basic concepts, design guidelines, and recent developments at millimeter-wave frequencies," International Journal of Antennas and Propagation, vol. 2016, Article ID 6075680, 20 pages, 2016.

[3] A. A. Kishk, "Dielectric resonator antenna, a candidate for radar applications," in Proceedings of the 2003 IEEE Radar Conference (Cat. No. 03CH37474), pp. 258-264, Huntsville, AL, USA, May 2003.

[4] M. Mrnka and Z. Raida, "Enhanced-gain dielectric resonator antenna based on the combination of higher-order modes," IEEE Antennas and Wireless Propagation Letters, vol. 15, pp. 710-713, 2016.

[5] R. Cicchetti, A. Faraone, E. Miozzi, R. Ravanelli, and O. Testa, "A high-gain mushroom-shaped dielectric resonator antenna for wideband wireless applications," IEEE Transactions on Antennas and Propagation, vol. 64, no. 7, pp. 2848-2861, 2016.

[6] A. S. Al-Zoubi, A. A. Kishk, and A. W. Glisson, "Aperture coupled rectangular dielectric resonator antenna array fed by dielectric image guide," IEEE Transactions on Antennas and Propagation, vol. 57, no. 8, pp. 2252-2259, 2009.

[7] A. S. Al-Zoubi, A. A. Kishk, and A. W. Glisson, "A linear rectangular dielectric resonator antenna array fed by dielectric image guide with low cross polarization," IEEE Transactions on Antennas and Propagation, vol. 58, no. 3, pp. 697-705, 2010.

[8] L. Jin, R. Lee, and I. Robertson, "A dielectric resonator antenna array using dielectric insular image guide," IEEE Transactions on Antennas and Propagation, vol. 63, no. 2, pp. 859-862, 2015.

[9] J. Lin, W. Shen, and K. Yang, "A low-sidelobe and wideband series-fed linear dielectric resonator antenna array," 
IEEE Antennas and Wireless Propagation Letters, vol. 16, pp. 513-516, 2017.

[10] M. R. Nikkhah, J. Rashed-Mohassel, and A. A. Kishk, "Highgain aperture coupled rectangular dielectric resonator antenna array using parasitic elements," IEEE Transactions on Antennas and Propagation, vol. 61, no. 7, pp. 3905-3908, 2013.

[11] H. Nawaz and A. Kiyani, "Ku-band dielectric resonator antenna array for microwave imaging," Microwave and Optical Technology Letters, vol. 58, no. 7, pp. 1651-1655, 2016.

[12] B. Rana and S. K. Parui, "Nonresonant microstrip patch-fed dielectric resonator antenna array," IEEE Antennas and Wireless Propagation Letters, vol. 14, pp. 747-750, 2015.

[13] W. M. Abdel-Wahab, S. Safavi-Naeini, and D. Busuioc, "Modeling and design of millimeter-wave high $Q$-factor parallel feeding scheme for dielectric resonator antenna arrays," IEEE Antennas and Wireless Propagation Letters, vol. 10, pp. 53-55, 2011.

[14] W. M. Abdel-Wahab, D. Busuioc, and S. Safavi-Naeini, "Millimeter-wave high radiation efficiency planar waveguide series-fed dielectric resonator antenna (DRA) array: analysis, design, and measurements," IEEE Transactions on Antennas and Propagation, vol. 59, no. 8, pp. 2834-2843, 2011.

[15] W. M. Abdel-Wahab, Y. Wang, and S. Safavi-Naeini, "SIW hybrid feeding network-integrated 2-D DRA array: simulations and experiments," IEEE Antennas and Wireless Propagation Letters, vol. 15, pp. 548-551, 2016.

[16] M. Su, L. Yuan, and Y. Liu, "A linearly polarized radial-line dielectric resonator antenna array," IEEE Antennas and Wireless Propagation Letters, vol. 16, pp. 788-791, 2017.

[17] J. Lin, W. Shen, Z. Shi, and S. Zhong, "Circularly polarized dielectric resonator antenna arrays with fractal cross-slotcoupled DRA elements," International Journal of Antennas and Propagation, vol. 2017, Article ID 8160768, 11 pages, 2017.

[18] H. Chu and Y. Guo, "A novel approach for millimeter-wave dielectric resonator antenna array designs by using the substrate integrated technology," IEEE Transactions on Antennas and Propagation, vol. 65, no. 2, pp. 909-914, 2017.

[19] K. Gong and X. H. Hu, "Low-profile substrate integrated dielectric resonator antenna implemented with PCB process," IEEE Antennas and Wireless Propagation Letters, vol. 13, pp. 1023-1026, 2014.

[20] M. Bozzi, A. Georgiadis, and K. Wu, "Review of substrateintegrated waveguide circuits and antennas," IET Microwaves, Antennas \& Propagation, vol. 5, no. 8, p. 909, 2011.

[21] R. K. Mongia and A. Ittipiboon, "Theoretical and experimental investigations on rectangular dielectric resonator antennas," IEEE Transactions on Antennas and Propagation, vol. 45, no. 9, pp. 1348-1356, 1997. 


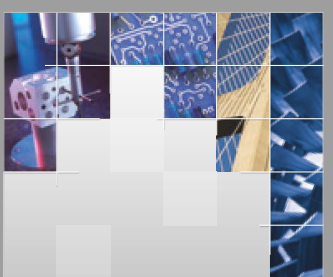

\section{Enfincering}
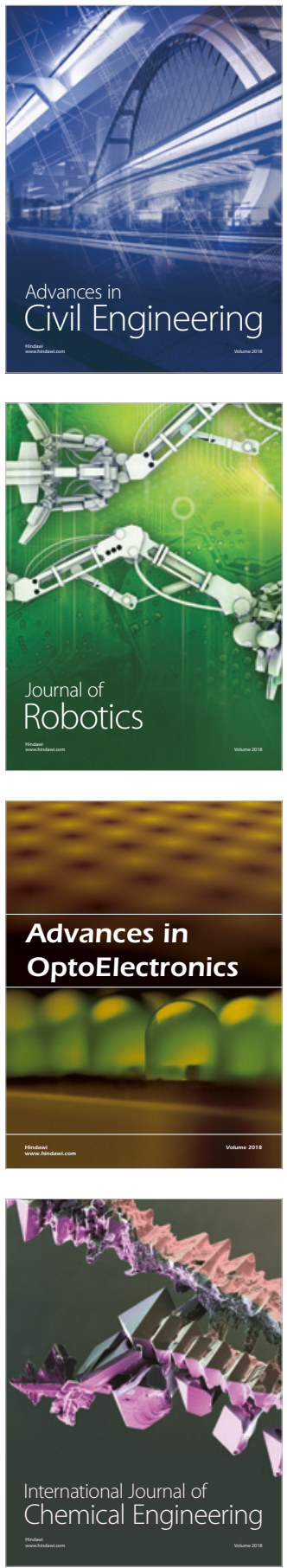

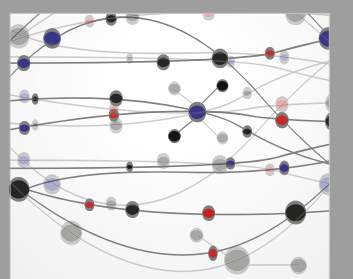

\section{Rotating \\ Machinery}

The Scientific World Journal

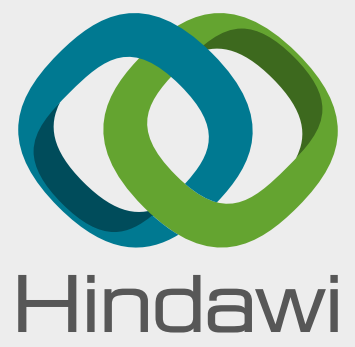

Submit your manuscripts at

www.hindawi.com
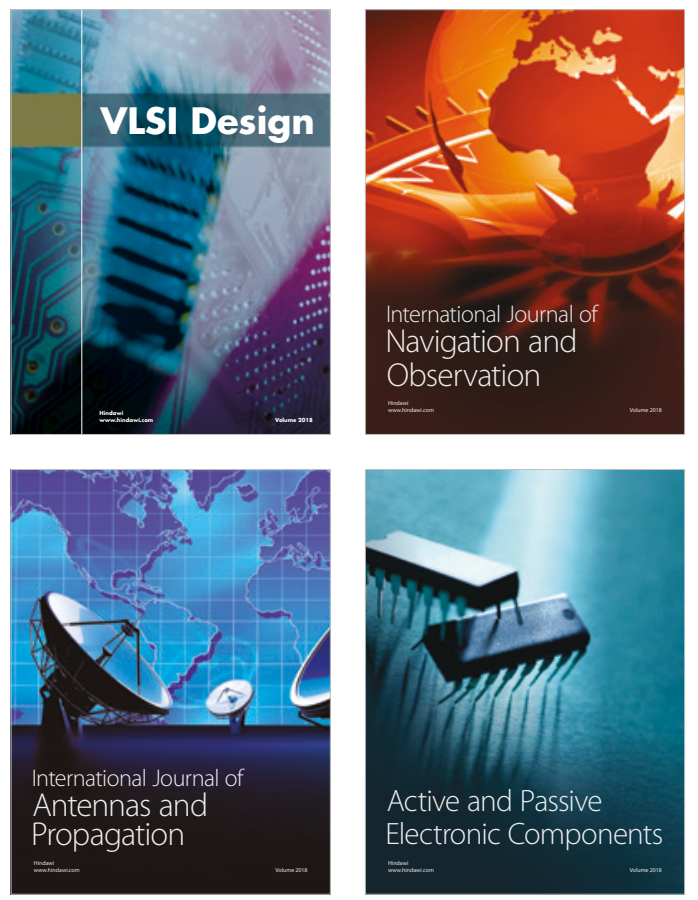
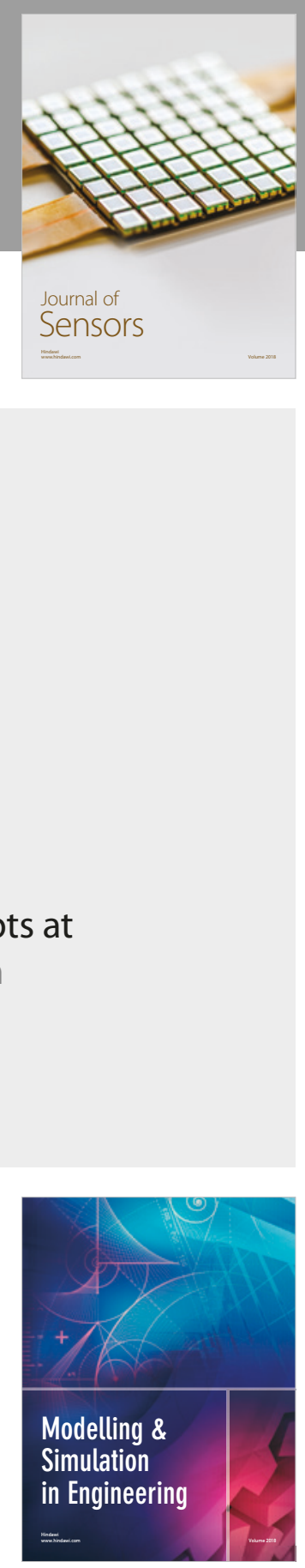

\section{Advances \\ Multimedia}
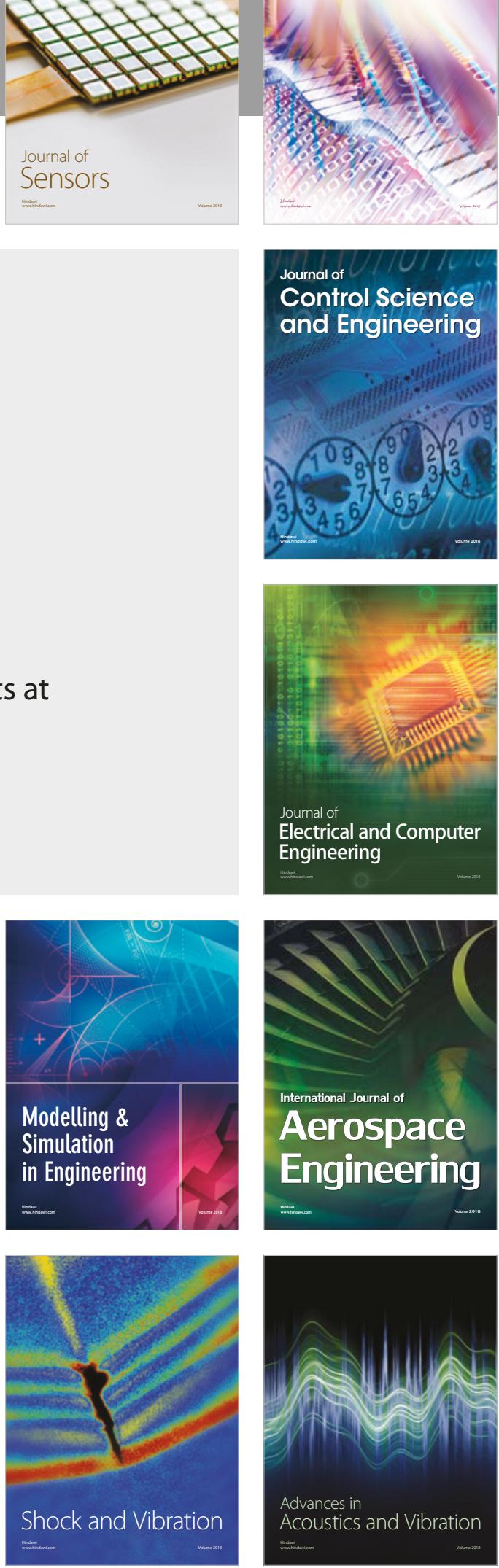